\title{
Where are the Real Trend Setters?
}

\section{Deepti Pant*}

IMS-Design Innovation Academy, India

Received: 盋 March 01, 2018; Published:

*Corresponding author: Deepti Pant, Executive Director, IMS - Design Innovation Academy, Noida, India, Tel: 919910114584 ; Email: pant.deepti@gmail.com

\section{Editorial}

Trend is word that has a fleeting meaning but is it? When a trend is seen coming on the surface of the society then it is more than what people need or desire. It is an expression of their culture, their social needs and their creative expression.

\section{Trends Indeed is Unfolding of a Hidden Myth, Ritual or Culture}

When the trend of corset came in 1910 it brought in a new culture in the society. It takes the idea that pain is beauty to a whole new level. A whole new industry was build round it. Not just this but a culture, a life style and a cosmology were created. But what happens when a trend dies. It has a particular poignancy. I wonder at times, why does not all trend stay in the society, is it not a loss of diversity, a heritage and a thought process.

\section{When does trend move into being a Heritage and What do we do to that Trend as a Society}

Some 880 trends died this century, I was reading somewhere. There is fatalism behind these numbers. Isn't it a way of life lost? The danger is to the small industries that get set up to sustain that trend. Why isn't this seed taken forward? When we do trend analysis, then what do we calculate. We search the reasons of its evolution and its growth and then fading out. But do we also take

in consideration of the loss of culture, myth and storytelling when a trend dies. As a storyteller I have often wondered, would we have had the story of Ras leela of Lord Krishna, if the trend of community bathing was not there in ancient Indian culture. Because when that trend disappeared, well so did the stories of Ras leela (Figure 1). And we have to be aware of the fact that trends of fashion and print evolve from the community or social trends as we call it. For example during the Jazz Age, Cloche hat became increasingly popular because women loved the look of cloche hat paired with their Eton cropped hair.

But how do we not let off those trends which are heritage and iconic. It's like death of languages, a culture and a context gone forever. Is keeping them in museums and encyclopaedia enough or should we not utilise them as platforms of innovation, growth and experimentation. Each and every trend is a sign that society is expressing itself and that social fabric is democratic enough to allow individuality to flourish and expand. Not only this, we need to create kaleidoscopic places where different trends are juxtaposed and one switch between them as we shift contexts. Translation of a trend into a new interface is an important act of holding the myth of that trend together and giving it a life so as to organically evolve into a new user experience, keeping the natural flow and essence of trend alive.

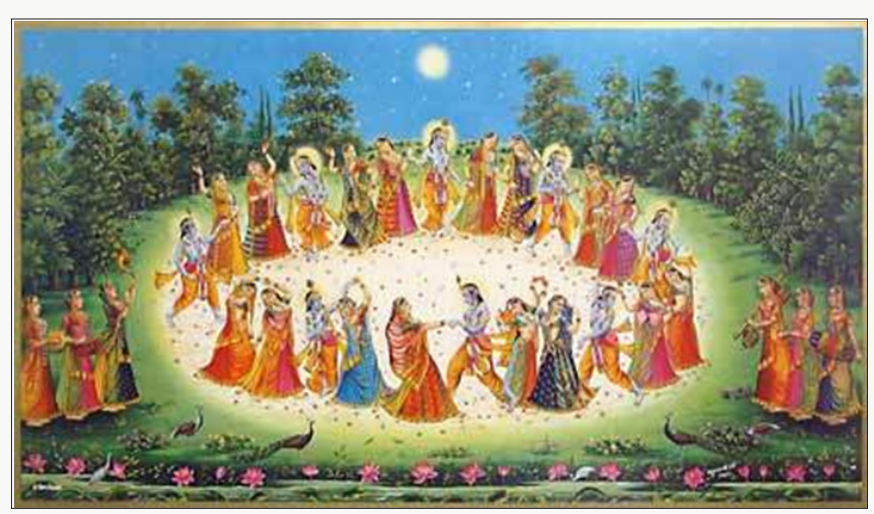

Figure 1: Raas Leela. 


\section{We need to invent Cultural Citizenships as a part of our Creative Imagination}

There is a tribe in hills of Kumaon, in India which has its own tantric prints for the bridal dresses. I clearly remember it being a part of everyday ritual till I was a young design research student but now we see people making it into a heritage property and those iconic prints are now on the verge of extinction. (Figure 2). A world that fails to be inventive about its own culture and stories eventually will be reduced to rudimentary, technical and structured living where fashion, beauty and myths have no place. Another thing that has guaranteed the disappearance of organic growth of trends is the structured curriculums of the design institutes. It is very interesting to note that a group of design students might be seen wearing same trends aspired by vogue and Bollywood where as a illiterate worker even with his meagre sum will be seen more differently and culturally dressed in many a different ways. Why is it so?

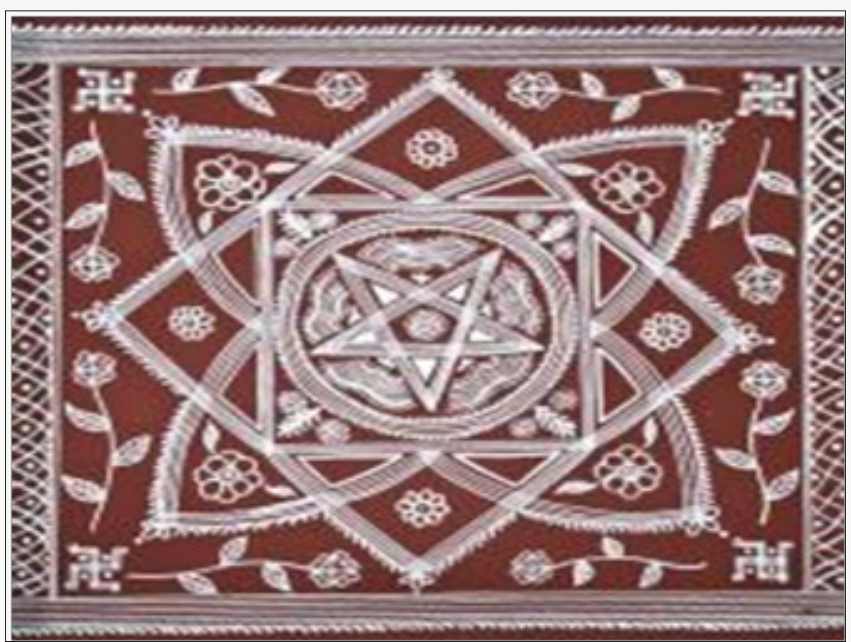

Figure 2: 3 Kumaon Aipans.

India and many such countries that have more than 3000 years of cultural history need to create a new social and creative consolidation to keep the pluralism of trends and self expression alive. Else trends coming and going will no longer be multi dimensional and multi cultural but will be centralised and of a single context and lifestyle. And the world will lose its creative spectrum. One needs to move to more polyglot world to sustain diversity of expression, lifestyle and experiences. I have also noted that death of trend and its social culture often go together. In India, many textile design trends are dying out as their cultures and villages are getting engulfed by cities, Television and internet. The intrusion of the corporate world is pushing them inward and in that processes each community is losing its expression and hence stopping the trend to evolve and come into surface of the society. No corporate or government thinks that loss of self expression (trend) by a group of people is something to be worried about.

People need to feel free to create their own trends and be able to nurture it. They need to feel that self expression in many different ways is relevant, posses' dignity, defines competence and is an important way of survival and growth. A trend disappears as new generation enters modernity, abandoning memory and older ways of life and living. So we in our own ways of development and growth need to keep the diversity alive and form a social and cultural fabric where people who are edgy, trend creators can become more expressive and prolific. Come let us become a trendy world, in the real sense of culture, diversity and history- A world where trends evolve from the real self expression of people, culture and experiences.

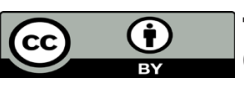

This work is licensed under Creative Commons Attribution 4.0 License

To Submit Your Article Click Here: Submit Article

DOI: $10.32474 /$ LTTFD.2018.01.000122

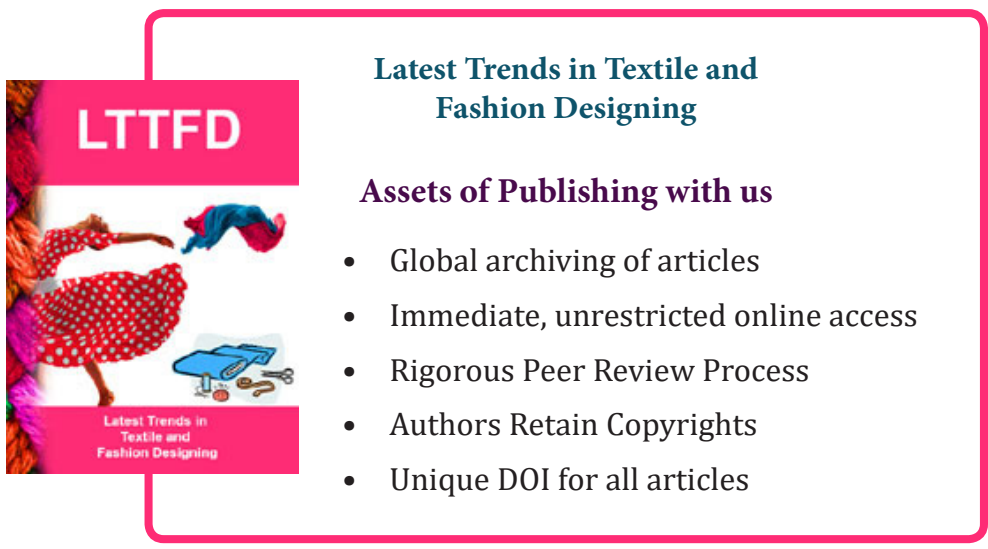

